This item was submitted to Loughborough's Research Repository by the author.

Items in Figshare are protected by copyright, with all rights reserved, unless otherwise indicated.

\title{
Facilitating participation in health-enhancing physical activity: a qualitative study of parkrun
}

PLEASE CITE THE PUBLISHED VERSION

http://dx.doi.org/10.1007/s12529-014-9431-5

\section{PUBLISHER}

Springer ( ) International Society of Behavioral Medicine

VERSION

AM (Accepted Manuscript)

\section{PUBLISHER STATEMENT}

This work is made available according to the conditions of the Creative Commons Attribution-NonCommercialNoDerivatives 4.0 International (CC BY-NC-ND 4.0) licence. Full details of this licence are available at: https://creativecommons.org/licenses/by-nc-nd/4.0/

\section{LICENCE}

CC BY-NC-ND 4.0

\section{REPOSITORY RECORD}

Stevinson, Clare, Gareth Wiltshire, and Mary Hickson. 2019. "Facilitating Participation in Health-enhancing Physical Activity: A Qualitative Study of Parkrun”. figshare. https://hdl.handle.net/2134/16090. 
This is a pre-copy-edited version of a paper published in the International Journal of Behavioural Medicine. The full citation is:

Stevinson C, Wiltshire G, Hickson M. Facilitating participation in health-enhancing physical activity: a qualitative study of parkrun. Int J Behav Med 2014 (advance e-publication)

\section{Title}

Facilitating participation in health-enhancing physical activity: a qualitative study of parkrun

\section{Authors}

Clare Stevinson $^{1}$, Gareth Wiltshire ${ }^{2}$, Mary Hickson ${ }^{3}$

${ }^{1}$ School of Sport, Exercise and Health Sciences, Loughborough University,

Loughborough, Leicestershire, LE11 3TU, United Kingdom

E-mail: C.D.Stevinson@lboro.ac.uk

${ }^{2}$ School of Sport, Exercise and Health Sciences, Loughborough University,

Loughborough, Leicestershire, LE11 3TU, United Kingdom

E-mail: G.Wiltshire@lboro.ac.uk

${ }^{3}$ Imperial College NHS Healthcare Trust, Dietetic Department, 13th Floor Lab Block,

Charing Cross Hospital, Fulham Palace Road, London, W6 8RF, United Kingdom

Email: mary.hickson@imperial.nhs.uk

\section{Corresponding author}

Clare Stevinson, School of Sport, Exercise and Health Sciences, Loughborough University, Loughborough, Leicestershire, LE11 3TU, United Kingdom

Tel: 01509 223255; E-mail: C.D.Stevinson@lboro.ac.uk 


\section{Abstract}

Purpose: Public health guidelines emphasise the value of vigorous intensity physical activity, but participation levels are low. This study was aimed at identifying factors contributing to initial and sustained engagement in parkrun in the United Kingdom, to inform the design of community-based interventions promoting health-enhancing physical activity.

Methods: Semi-structured interviews were conducted by telephone with 48 adult participants of parkrun, a national network of weekly, free, volunteer-led, timed $5 \mathrm{~km}$ runs in public spaces. The framework approach was used for thematic analysis of transcripts.

Results: Two overarching themes emerged: freedom and reciprocity. Freedom referred to the accessibility and inclusivity of events, both of which contributed to initial attendance and sustained involvement. Reciprocity related to the dual opportunity for personal gain and for helping others. Anticipation of fitness and health benefits were important for initial motivation. However, additional aspects motivating continued involvement included achievement of time or attendance goals, social cohesion, and contributing to the community. Conclusions: Specific features of the parkrun experience encouraged participation including the accessible, inclusive ethos, achievement opportunities, and inherent social support, along with the outdoor natural settings, and integrated volunteer system. The inclusion of these elements in community-based interventions may increase success in initiating and maintaining health-enhancing physical activity.

Keywords: physical activity, exercise, community, well-being, qualitative research 


\section{Background}

There is strong evidence that physical activity helps to prevent several major diseases including coronary heart disease, stroke, type II diabetes, osteoporosis, some cancers, obesity, and mental illness [1]. Overall, inactivity has been identified as the fourth leading risk factor for premature mortality, accounting for $6 \%$ of deaths globally [2]. For the United Kingdom (UK), the current public health guidelines are based on a weekly total of at least 150 minutes of moderately intense activity or 75 minutes of vigorous activity, or an equivalent combination of moderate and vigorous intensity activity spread throughout the week, in bouts of at least 10 minutes [3]. However, the numbers achieving these targets are low, with selfreported data from the four home nations suggesting that around a third of adults meet the recommendations [3].

Despite various initiatives and programmes aimed at promoting physical activity in the population, there is limited evidence of the optimal approach. The best results have come from comprehensive and intensive programmes involving individualised exercise prescriptions, counselling, and educational materials, with follow-up sessions and booster strategies [4]. However, initial increases in physical activity and fitness were not sustained long-term in these studies, and comprehensive intervention programmes have proved the least cost-effective from the public health perspective [5, 6]. Notably in the UK, community-based physical activity interventions have been identified as representing a worthwhile investment in terms of healthcare savings [7]. In particular, mass participation events involving exercise (e.g. charity bicycle rides and fun runs) have been suggested as a potential public health resource by motivating physical activity via social engagement [8].

One such event that has shown this potential is parkrun: a fast-growing international network of free, weekly, timed 5km runs in public spaces [9]. Organised by volunteer teams, parkrun aims to promote physical activity and community spirit, by providing supportive opportunities for exercise. As a not-for-profit organisation, parkrun relies on core sponsorship to cover the salary costs of administrative staff, the web-based infrastructure for registration and results, and support for the set-up of new events. A survey of 7308 participants across 130 different parkruns in the UK, indicated that the majority were not regular joggers or runners before attending a parkrun event, and that these individuals were most likely to demonstrate fitness improvements, and report benefits in health, weight control, mental wellbeing, and confidence for running. Participants had been attending parkrun for a median of 12 months at the time of the study [10]. Several features of parkrun may make it particularly 
valuable as a public health intervention. These include the encouragement of vigorous exercise (jogging/running) which confers greater health benefits than lower intensity physical activity [11], and is emphasised in the guidelines [3]. Furthermore, the integrated volunteer system, enabling participants to contribute to the sustainability of their local event, ensures the on-going weekly opportunity and support for activity year-round. Finally, barriers to participation are minimised as far as possible, with no upper or lower age-limit, no special clothing or equipment required, a simple one-off registration process, and no direct costs.

The extent to which these, and other factors associated with parkrun, may contribute to the adoption and maintenance of physical activity among members of the local community, has not been investigated. Identifying successful elements could help inform the design of community-based interventions for physical activity promotion. The current study therefore explored the personal motives and experiences of individuals taking part in parkrun, with the aim of identifying aspects that encouraged initial participation and contributed to sustained involvement in health-enhancing physical activity.

\section{Methods}

Approval was granted by Loughborough University Ethical Advisory Committee to conduct semi-structured interviews by telephone with adult participants of parkrun between June and August 2012. All respondents $(n=7308)$ to a national survey about parkrun involvement [10] were invited to volunteer for an additional interview for the current study. To be eligible, volunteers had to be at least 18 years old, registered for parkrun, and provide informed consent to a recorded interview by telephone. Participants were informed that all data would be anonymised, and seen only by the research team.

To ensure that interviewees were included from across the spectrum of parkrun participants, a sampling matrix based on age, gender, running experience, and geographic location, was used to purposively select individuals. A target quota of eight males and females in each of three age groups (younger, middle-aged, and older, adults) formed the basis, with the aim of including individuals from each broad category of prior running experience (some or none), and location (North, Midlands, South). Selected individuals were sent an e-mail invitation, with non-responders or decliners replaced with the next volunteer in the appropriate section of the sampling frame. 
Interviews were conducted by one of three qualitative researchers not known to participants, using a semi-structured topic guide. The guide included a loose schedule of open-ended questions and probes around participants' attitudes and involvement regarding physical activity (e.g. Does physical activity matter to you personally?), motives for attending parkrun (e.g. What led to you first going to parkrun? Are these reasons still the same now?), the physical and social environment of parkrun, (e.g., Can you tell me about the atmosphere at events?), and any positive or negative outcomes or observations (e.g. Do you feel that anything has changed for you from attending parkrun?). All interviews were digitally recorded and transcribed verbatim, with any personal information deleted to preserve anonymity.

Data analysis was performed by a researcher with training and experience in qualitative research, using the framework approach [12]. This involved an initial phase of familiarisation, involving listening to audio files and reading transcripts, while taking notes on key observations and recurrent points. These notes were used in the next phase of thematic framework development to develop a provisional set of headings under which data could be organised. During the indexing phase, this preliminary framework was applied to each transcript to refine the hierarchical structure through merging or adding categories. Microsoft Excel 2010 (Microsoft Corporation, Redmond, WA, United States) was used for abstracting data from each individual transcript into a series of charts, each one representing a superordinate category (e.g. physical activity) with a number of sub-headings (e.g. history, motivation). Finally, in the mapping and interpretation stage, charts were systematically reviewed to examine patterns in the data and implicit connections between ideas, and identify higher and lower order themes. A second researcher also reviewed transcripts, and met with the primary analyst to discuss and agree the interpretation of results.

\section{Results}

A total of 2791 survey participants volunteered to be interviewed (38.2\% of the total survey sample). Over the recruitment period, 100 respondents were invited to the study with 37 not responding, and a further 15 declining to take part. Interviews were conducted with 48 individuals ( 23 male; 25 female) with interview length ranging from 25 to 44 minutes. Participant characteristics are summarised in Table 1, representing a broad sample based on age, prior running experience, geographic location, weight status, and parkrun attendance length. 
Two dominant broad themes (freedom and reciprocity) emerged from the individual accounts that help understand the integral features of parkrun that facilitated participation. Table 2 summarises the nature of these themes and their importance for initial attendance and sustained involvement. These are described in the text with illustrative quotes provided in Tables 3 and 4 .

The freedom theme was particularly important for initial attendance, and also contributed to maintenance of involvement. This referred to the overall flexibility and approachability to participation that minimised some of the common barriers associated with physical activity engagement. Elements of the accessibility sub-theme were mentioned by almost all participants and included the simple free set-up, convenient time and location, and the ongoing opportunity to turn up when desired, without overt commitment or pressure to attend or perform (Table 3).

The other strong contributor to the theme of freedom was the perceived inclusivity of parkrun. The diversity of participants in terms of age, background, and running ability, made parkrun feel equally welcoming to all members of the community (Table 3). This encouraged people to initially attend as well as made them feel comfortable and want to return. Over a third of participants spontaneously mentioned a unique feature of parkrun being the opportunity for generations of families to exercise together, with this even extending to babies in pushchairs and pet dogs.

The reciprocity theme related to the unique feature of parkrun that combined opportunities for personal gain, alongside opportunities for helping others to also benefit. All participants described their initial attendance being motivated by the anticipation of potential gains (typically in terms of fitness, weight, or health). Although achieving these outcomes also contributed to the motivation for continued involvement, additional aspects had a stronger influence on sustaining participation by making attendance a rewarding or enjoyable experience (Table 4). One of these elements was the social interaction opportunities available through parkrun. The range of experiences included enjoying one-off friendly encounters, developing casual acquaintances, and even forming lasting friendships. Another factor contributing to the enjoyment associated with parkrun was the natural physical environment in which events take place. Over half the participants discussed how being outdoors in the 
fresh air among beautiful scenery brought additional pleasure to the experience that increased the desire to return each week.

Another significant motivator of continued participation was the sense of achievement fostered through improvements in performance, or regular attendance. These could be monitored via the online results system that generates automatic e-mails and text messages post-run, and provides a weekly update of each individual's history highlighting improvements in times and landmarks of 50 and 100 runs. All participants referred to selfimprovement in terms of achieving faster times, progressing to be able to run the entire course, or reaching attendance milestones. Several participants reported that these goals motivated them to exercise independently at other times of the week, and over a third reported that parkrun had led to the development of new identity as a runner, and had encouraged them to enter races or join a club. Despite the overwhelming focus on selfcomparison for achievement, a small proportion (four women and four men) described how the opportunity for friendly rivalries with others of a similar pace appealed to their competitive tendencies and strengthened their motivation.

Interestingly, in addition to the direct personal and social benefits, all participants referred to the importance and appeal of the opportunities to make a reciprocal contribution to parkrun (Table 4). This was particularly evident in relation to the social support discussed by almost all participants. The encouragement received from other runners was described as instrumental in increasing confidence and motivation, and the desire and importance for offering the same support to others was emphasised. In some cases, this extended to providing inspiration for other runners, both faster and slower than themselves. There were instances of slower participants feeling inspired by the speed of front-runners, and sometimes seeing international runners taking part in the same run. Conversely, faster runners described how they admired and respected the efforts of those for whom running did not come easily, and were happy to offer advice.

The parkrun volunteer system proved central in satisfying the desire to give back to the event in enabling participants to return the favour to those who volunteered on other weeks. The opportunity to contribute to the sustainability of the free events through marshalling, or laying out the course, strengthened the feeling of involvement in a community project. A few individuals described their sense of connection to the overall philosophy of parkrun, with 
additional contributions including donations or fundraising for the event or the park. One participant reported how he favoured the sponsors because of their support of parkrun.

Throughout the core themes of freedom and reciprocity, it was evident that for many participants, parkrun was an exercise opportunity that had positive differences to traditional approaches such as attending a fitness centre or sports club (Table 5). This included the absence of binding fees or expectations to attend, and the less intimidating atmosphere that emphasised participation not performance. The opportunities for social interaction and integration were also discussed which contrasted with the anonymous feel of some other situations. Finally, the outdoor natural environment of parkrun was highlighted as an attractive feature over some conventional indoor settings.

Despite specific questions, all participants reported no adverse experiences or perceptions of parkrun. Upon further probing a few individuals offered examples of negative aspects relating to the park setting (e.g. hilly or muddy terrain, limited parking or toilets), or the occasional rude runner.

\section{Discussion}

In exploring factors that encouraged initial and sustained attendance at parkrun, this study helps to identify features that could be included in community-based interventions for increasing physical activity. Within the two broad themes identified (freedom and reciprocity), several specific factors emerged as important.

Initial participation was facilitated by the perceived accessibility (i.e. convenient location and time, no cost or commitment, simple registration), along with the understanding that the event was inclusive of all abilities, ages, and backgrounds. These factors served to minimise the most common barriers to exercise, which for UK adults, are reported as time restraints, lacking a 'sporty' image, and looking after children [13]. Parenthood has been consistently associated with lower physical activity levels, largely due to prioritising children's activities [14]. Therefore the inclusive family-orientated nature of parkrun where all age-groups can be involved as a participant, volunteer, or supporter, emerged as an important facilitator.

Alongside the accessible, approachable format, the potential benefits of taking part in parkrun motivated initial attendance, and contributed to continued involvement. Consistent with previous studies of exercise motivation [15], participants identified health and well-being 
benefits, social opportunities, and feelings of achievement, as strongly influential. The value of the individualised record of attendance and performance at parkrun was notable. Drawing on established behavioural techniques of goal-setting and self-monitoring [16], this provided opportunities for personal competence challenges (e.g. improving times, running the whole distance, or reaching milestones of 50 or 100 runs). Setting these targets provided on-going motivation for parkrun attendance and independent exercise, which is compatible with evidence that mastery goals are generally associated with positive outcomes such as effort and persistence [17]. Similarly, pursuing these goals may have helped develop an identity as a runner for some individuals, since perceptions of commitment and improvement are direct contributors to changes in exercise identity $[18,19]$. This is facilitated by parkrun providing the means for fostering positive mastery experiences for increasing confidence for exercise. According to self-efficacy theory, interventions need to help individuals set goals, selfmonitor behaviour, and use social support in order to maintain a challenging behaviour such as exercise [20].

Both the social and physical environment of parkrun were identified as significant contributors to the positive experience of parkrun that encouraged repeat attendance. The friendly atmosphere and opportunities for social contact were central to this, and for many participants had led to parkrun becoming an important social network. Considerable evidence supports the impact of positive social relationships on psychological health [21], and exercise adherence [22].

Additionally, the outdoor natural settings in which events are held contributed to the appeal of participation. Participants discussed how being outdoors unconstrained in the fresh air among beautiful scenery brought additional enjoyment to the exercise experience that increased the desire to continue with it. The importance of the setting is supported by research specifically highlighting the role of parks in the community for facilitating physical activity [23, 24], and the value of exercising outdoors to mental health [25]. Furthermore, exposure to green space is associated with psychological well-being [26, 27], and has been identified as having a potential role in reducing socioeconomic health inequalities [28].

It is interesting to note the transition in motivation reported over time. Although initial attendance motives were most commonly health and fitness related, additional factors became important in understanding continued attendance, such as social and environmental feedback that contributed to a sense of well-being. These observations are compatible with previous 
research showing that the rewards of exercise that are most immediate (e.g. quality of life), may be more powerful in motivating exercise adherence than more distant benefits such as weight and health [29].

In addition to the personal benefits of taking part, a distinctive and valued characteristic of parkrun was the opportunity to reciprocate these gains. This was achieved most directly by the volunteer system that represents an effective mechanism for sustaining a free event, but importantly also provides participation opportunities even for those not able to take part in the run. In addition, volunteering added to many individuals' enjoyment of participation, which is consistent with a body of research suggesting that volunteer activities are associated with well-being [30]. Other ways through which participants made reciprocal contributions included providing support, advice, and encouragement to other runners, and donating or fundraising for their event. These observations suggest that the success of parkrun is partly underpinned by the principles of social exchange theory [31], which holds that much social behaviour is determined by a perceived balance of giving and taking (the norm of reciprocity).

Representing a social exchange is one aspect of parkrun that separates it from some traditional exercise opportunities that are based on a conventional economic exchange through charging entry or membership fees. Interestingly, the freedom and flexibility of parkrun with no attendance requirements, may lead to greater exercise participation for some individuals, because of the lack of commitment required. Some were dissuaded from signing up to exercise options involving advance subscriptions, or a reliance on team members, that create a perceived obligation to attend. Instead, attendance at parkrun represented a more autonomous commitment. These experiences are supported by evidence that autonomous motives, particularly intrinsic values, are predictive of exercise maintenance [32].

The social and physical environmental context of parkrun was also highlighted as contrasting with the anonymous feel of some other exercise settings. Interestingly, these observations and the other evidence for the features of parkrun influencing participation, did not reveal any clear differences between men and women, or between those with and without prior running experience. This supports existing evidence that parkrun eliminates some of the traditional deterrents to physical activity for women and novice exercisers [10]. 


\section{Implications for interventions promoting physical activity}

Notably, the influential features identified in this study align closely to the findings of an evidence-based report of the factors that contribute most strongly to personal well-being [33]. The factors identified were physical activity, social networks, natural world, personal challenges, and helping others. Enhanced psychological well-being was one of the strongest outcomes of parkrun participation reported in an earlier study [10], and the qualitative data reported here, suggest that these five elements are important contributors to attendance. Accordingly, several characteristics of parkrun that are central to the ease and enjoyment of participation can be recommended for other interventions aimed at promoting healthenhancing physical activity. Firstly, an accessible and inclusive set-up that minimises perceived barriers to exercise (e.g. cost, time, age, ability) is crucial to encouraging initial participation. Secondly, the provision of achievement opportunities with self-monitoring tools that encourage self-referenced improvement lead to increased confidence and motivation for sustained participation. Thirdly, a supportive social environment engenders additional desire to attend beyond health and fitness goals. Fourthly, outdoor scenic settings that take advantage of the documented added-value of the natural environment, contribute to enjoyment and engagement. Finally, an integrated opportunity to contribute to the intervention, such as volunteering for aspects of the organisation, has dual benefits. Not only does this help with the sustainability of a low-cost intervention, but also generates a sense of belonging that motivates participation.

\section{Study strengths and limitations}

The strength of qualitative research, in providing rich descriptive data on the experiences of participants, can also be seen as its main weakness, in making the generality of results difficult to establish, and risking 'anecdotalism' [34]. Means of minimising this risk in the study included the use of a sampling matrix for recruitment, a semi-structured guide for interviews, and a transparent and comprehensive approach for data analysis. However, a notable limitation surrounds the lack of negative experiences reported despite specific probes, suggesting that the individuals volunteering to be interviewed for the study did not include those for whom parkrun may have been de-motivating. Nonetheless, as the first qualitative investigation of parkrun, this study has provided evidence that can inform the design of interventions for promoting physical activity in the community. Future research would be aimed at testing the effectiveness of the specific features identified here, and examining differences between those with and without prior exercise experience. 


\section{Conclusions}

As a rapidly-growing international series of events aimed at increasing physical activity and well-being in the community, parkrun has several features that contribute to its success.

These include the accessible, inclusive ethos, achievement opportunities, and inherent social support, along with the outdoor natural settings, and integrated volunteer system. The inclusion of these elements in community-based interventions may increase success in initiating and maintaining health-enhancing physical activity. 


\section{Acknowledgements}

We thank Danielle Mellows and Eleanor Wilkinson for conducting interviews, parkrun for covering the costs of transcription, and all participants for sharing their experiences.

\section{Ethical standards}

All procedures followed were in accordance with the ethical standards of the responsible committee on human experimentation (institutional and national) and with the Helsinki Declaration of 1975, as revised in 2000. Informed consent was obtained from all participants included in the study.

\section{Conflict of interest}

Clare Stevinson and Gareth Wiltshire declare no conflicts of interest. Mary Hickson is married to an employee of parkrun. Costs of transcription were covered by parkrun. No other funding was available for this study. There was no involvement from parkrun personnel in study design, data collection, data analysis, data interpretation, manuscript writing, or choice of journal. 


\section{References}

1. O'Donovan G, Blazevich AJ, Boreham C, Cooper AR, Crank H, Ekelund U, Fox KR, Gately P, Giles-Corti B, Gill JM, Hamer M, McDermott I, Murphy M, Mutrie N, Reilly JJ, Saxton JM, Stamatakis E. The ABC of physical activity for health: a consensus statement from the British Association of Sport and Exercise Sciences. J Sport Sci. 2010;28:573-91.

2. World Health Organization. Global Recommendations on Physical Activity for Health. Geneva: WHO; 2010.

3. Chief Medical Officers of England, Scotland, Wales, and Northern Ireland. Start active, stay active: a report on physical activity for health from the four home countries' Chief Medical Officers. London: Department of Health; 2011.

4. Müller-Riemenschneider F, Reinhold T, Nocon M, Willich SN. Long term effectiveness of interventions promoting physical activity: a systematic review. Prev Med. 2008;47:354-68.

5. Müller-Riemenschneider F, Reinhold T, Willich SN. Cost-effectiveness of interventions promoting physical activity. Br J Sports Med. 2009;43:70-6.

6. Wu S, Cohen D, Shi Y, Pearson M, Sturm R. Economic analysis of physical activity interventions. Am J Prev Med. 2011;40:149-58.

7. Pringle A, Cooke C, Gilson N, Marsh K, McKenna J. Cost-effectiveness of interventions to improve moderate physical activity: A study in nine UK sites. Health Educ J. 2010;69:211-24.

8. Bauman A, Murphy N, Lane A. The role of community programmes and mass events in promoting physical activity to patients. Br J Sports Med. 2009;43:44-6.

9. parkrun. http://www.parkrun.com. Accessed 9 March 2014.

10. Stevinson C, Hickson M. Exploring the public health potential of a mass community participation event. J Pub Health. 2013 (advance e-publication: doi:10.1093/pubmed/fdt082).

11. Swain DP, Franklin BA. Comparison of cardioprotective benefits of vigorous versus moderate intensity aerobic exercise. Am J Cardiol. 2006;97:141-7.

12. Ritchie J, Spencer L, O’Conner W. Carrying out qualitative analysis. In: Ritchie J, Lewis J. (eds). Qualitative Research Practice. London: Sage Publications; 2007.

13. Zunft HJ, Friebe D, Seppelt B, Widhalm K, Remaut de Winter AM, Vaz de Almeida MD, Kearney JM, Gibney M. Perceived benefits and barriers to physical activity in a nationally representative sample in the European Union. Public Health Nutr. 1999;2:153-60. 
14. Bellows-Riecken KH, Rhodes RE. A birth of inactivity? A review of physical activity and parenthood. Prev Med. 2008;46:99-110.

15. Allender S, Cowburn G, Foster C. Understanding participation in sport and physical activity among children and adults: a review of qualitative studies. Health Educ Res. 2006;21:826-35.

16. Greaves CJ, Sheppard KE, Abraham C, Hardeman W, Roden M, Evans PH, Schwarz P; IMAGE Study Group. Systematic review of reviews of intervention components associated with increased effectiveness in dietary and physical activity interventions. BMC Public Health. 2011;11:119.

17. Biddle S, Wang CKJ, Kavussanu M, Spray C. Correlates of achievement goal orientations in physical activity: A systematic review of research. Eur J Sport Sci. 2003;3(5):1-20.

18. Kendzierski D, Furr RM, Schiavoni J. Physical activity self-definitions: correlates and perceived criteria. J Sport Exer Psychol. 1998;20: 176-93.

19. Kendzierski D, Morganstein MS. Test, revision, and cross-validation of the Physical Activity Self-Definition Model. J Sport Exerc Psychol. 2009;31:484-504.

20. Bandura A. Self-efficacy: the exercise of control. New York, NY: W.H. Freeman and Company; 1997.

21. Bowling A. Do older and younger people differ in their reported well-being? A national survey of adults in Britain. Fam Pract. 2011;28:145-55.

22. Bauman AE, Reis RS, Sallis JF, Wells JC, Loos RJ, Martin BW; Lancet Physical Activity Series Working Group. Correlates of physical activity: why are some people physically active and others not? Lancet. 2012;380:258-71.

23. Han B, Cohen D, McKenzie TL. Quantifying the contribution of neighbourhood parks to physical activity. Prev Med. 2013;57:483-7.

24. Broyles ST, Mowen AJ, Theall KP, Gustat J, Rung AL. Integrating social capital into a park-use and active-living framework. Am J Prev Med. 2011;40:522-29.

25. Thompson-Coon J, Boddy K, Stein K, Whear R, Barton J, Depledge MH. Does participating in physical activity in outdoor natural environments have a greater effect on physical and mental wellbeing than physical activity indoors? A systematic review. Environ Sci Technol. 2011;45:1761-72.

26. Barton J, Pretty J. What is the best dose of nature and green exercise for improving mental health? A multi-study analysis. Environ Sci Technol 2010;44:3947-55.

27. Ryan RM, Weinstein N, Bernstein J, Brown KW, Mistretta L, Gagne M. Vitalizing effects of being outdoors and in nature. J Environ Psychol. 2010;30:159-68. 
28. Mitchell R, Popham F. Effect of exposure to natural environment on health inequalities: an observational population study. Lancet 2008;372:1655-70.

29. Segar ML Segar ML, Eccles JS, Richardson CR. Rebranding exercise: closing the gap between values and behaviour. Int J Behav Nutr Phys Act. 2011;8:94.

30. Jenkinson CE, Dickens AP, Jones K, Thompson-Coon J, Taylor RS, Rogers M, Bambra CL, Lang I, Richards SH. Is volunteering a public health intervention? A systematic review and meta-analysis of the health and survival of volunteers. BMC Public Health. 2013;13:773.

31. Homans GC. Social behaviour as exchange. Am J Sociol. 1958;63:597-606.

32. Teixeira PJ, Carraça EV, Markland D, Silva MN, Ryan RM. Exercise, physical activity, and self-determination theory: A systematic review. Int J Behav Nutr Phys Act. 2012;9:78.

33. Aked J, Marks N, Cordon C, Thompson S. Five Ways to Wellbeing. London: The New Economics Foundation; 2010.

34. Silverman D. Interpreting qualitative data. London: Sage Publications; 2006. 
Table 1 Participant characteristics

\begin{tabular}{lccc}
\hline Characteristic & $\begin{array}{c}\text { Total } \\
(\mathrm{n}=48)\end{array}$ & $\begin{array}{c}\text { Males } \\
(\mathrm{n}=23)\end{array}$ & $\begin{array}{c}\text { Females } \\
(\mathrm{n}=25)\end{array}$ \\
\hline Age & 15 & 6 & 9 \\
18-44 years & 20 & 10 & 10 \\
$45-64$ years & 13 & 7 & 6 \\
$\geq 65$ years & & & \\
Prior running experience & 25 & 14 & 11 \\
Some running history & 23 & 9 & 14 \\
$\quad$ No running history & & & 9 \\
Geographic region & 16 & 7 & 13 \\
$\quad$ North of England, Scotland, Northern Ireland & 9 & 6 & \\
$\quad$ Midlands, East Anglia & 23 & 10 & 10 \\
South of England & & & 10 \\
Weight status & 17 & 7 & 5 \\
$\quad$ Normal weight & 20 & 10 & 10 \\
Overweight & 11 & 6 & 15 \\
$\quad$ Obese & & & \\
Duration of parkrun participation & 18 & 8 & \\
$\quad<12$ months & 30 & 15 & \\
$\geq 12$ months & & & \\
\hline
\end{tabular}


Table 2 Summary of key themes related to initial and sustained participation at parkrun

\begin{tabular}{|c|c|c|c|}
\hline Broad theme & Sub-theme & Initial participation & Sustained participation \\
\hline \multirow{4}{*}{$\begin{array}{l}\text { Freedom } \\
\text { (flexibility and } \\
\text { approachability } \\
\text { of opportunity) }\end{array}$} & Accessibility & $\begin{array}{l}\text { - Perceiving lack of } \\
\text { obligation to attend or }\end{array}$ & $\begin{array}{l}\text { - Being able to attend as desired } \\
\text { without planning. }\end{array}$ \\
\hline & & perform. & - Knowing that no pressure or \\
\hline & & $\begin{array}{l}\text { - Appreciating the simplicity } \\
\text { of entry and convenient } \\
\text { scheduling. }\end{array}$ & $\begin{array}{l}\text { expectation exists for effort or } \\
\text { performance level. }\end{array}$ \\
\hline & Inclusivity & $\begin{array}{l}\text { - Recognising that all } \\
\text { abilities, backgrounds, ages, } \\
\text { equally welcome. }\end{array}$ & $\begin{array}{l}\text { - Feeling accepted and integrated } \\
\text { at any age or ability level. }\end{array}$ \\
\hline \multirow{9}{*}{$\begin{array}{l}\text { Reciprocity } \\
\text { (dual } \\
\text { opportunity for } \\
\text { personal benefit } \\
\text { and helping } \\
\text { others) }\end{array}$} & Gaining & $\begin{array}{l}\text { - Anticipating fitness, weight, } \\
\text { health improvement. }\end{array}$ & $\begin{array}{l}\text { - Achieving fitness, weight, health } \\
\text { improvement }\end{array}$ \\
\hline & & & $\begin{array}{l}\text { - Enjoying social interaction and } \\
\text { friendship opportunities. }\end{array}$ \\
\hline & & & - Appreciating exposure to nature. \\
\hline & & & $\begin{array}{l}\text { - Feeling motivated by time and } \\
\text { attendance goals. }\end{array}$ \\
\hline & & & $\begin{array}{l}\text { - Developing confidence in } \\
\text { abilities, and identity as a runner. }\end{array}$ \\
\hline & Giving & & $\begin{array}{l}\text { - Encouraging and advising other } \\
\text { participants. }\end{array}$ \\
\hline & & & - Inspiring other participants. \\
\hline & & & $\begin{array}{l}\text { - Volunteering to sustain the } \\
\text { event. }\end{array}$ \\
\hline & & & • Fundraising for event or park. \\
\hline
\end{tabular}


Table 3 Illustrative quotes from the freedom theme

\section{Accessibility}

For me, pretty much nine o'clock on a Saturday morning is free time which means I can go, unlike six thirty on a weekday where I knew I could quite possibly still be working or travelling, and the fact that it is a structured time makes me more motivated to go.

[Interview 33: 40-year-old male; initial occasional runner; 13 months attendance]

It's free, it's all inclusive, it's easy, I can get there five minutes before I have to start running and I can leave immediately after, so it doesn't take up a lot of time.

[Interview 43: 33-year-old female; initial non-runner; 4 months attendance]

It's very easy to go along and I think part of the appeal is the fact that you're not committed every week. You know, it's not like you're paying for the event and you think "Oh, I must attend".

[Interview 12: 45-year-old male; initial non-runner; 12 months attendance]

It's free: that is a massive thing and it's always there on a Saturday morning, you know, and you're not obliged to go. You're not letting anybody down if you don't go and you can just turn up again. [Interview 11: 41-year-old female; initial non-runner; 12 months attendance]

It's very easy in that you just print off a barcode, there's no fee, it's absolutely free. There's no commitment if you turn up and you don't feel like running you haven't lost anything.

[Interview 23: 67-year-old female; initial regular runner; 25 months attendance]

It's the fact that almost, you know, it's not organised in a sense to do you good, or because anyone thinks you should do it, that is part of its appeal I think.

[Interview 2: 53-year-old male; initial non-runner; 59 months attendance]

\section{Inclusivity}

The youngest to the oldest must have been about 60 years. I think any event that can pull people in of all ages, backgrounds and fitness levels has to be a great idea.

[Interview 40: 47-year-old male; initial occasional runner; 33 months attendance]

I think because so many different types of people can do it. So you've got the very quick people at the start, but it's mainly the way it encourages people that haven't done exercise before to go out and give it a go.

[Interview 5: 43-year-old female; initial non-runner; 33 months attendance]

It isn't just fit, sporty running obsessed people who do it, there is a whole range of people who do parkrun which I think is great and it's very inclusive.

[Interview 43: 33-year-old female; initial non-runner; 4 months attendance]

It does not allow me to use the barrier "Oh I'm not going to be good enough" because it's so inclusive by involving everyone, and I know there are people who are slower that finish last every week, but still go and try.

[Interview 47: 30-year-old female; initial non-runner; 34 months attendance]

You see quite a lot of school kids there as well. I don't know that they're necessarily ones who'd be running at school.

[Interview 2: 53-year-old male, initial non-runner with 59 months attendance]

We go running with the dog and jog along with him. Other people do exactly the same. There are those that run with their kids in prams and everything else. You would never get that in any other kind of run.

[Interview 7: 61-year-old male; initial occasional runner; 26 months attendance] 
Table 4 Illustrative quotes from the reciprocity theme

\section{Gaining}

I found out I had diabetes so I needed to do exercise...so parkrun's really fitted in very well with that...it's really helped motivate me to manage my diabetes, so I'm really pleased about that.

[Interview 16: 46-year-old female; initial non-runner; 6 months attendance]

parkrun has definitely contributed to my weight loss which makes me feel great. I look back at where I was 18 months ago in terms of my size and athleticism, and every day I look back at the photos and am proud of what I have achieved.

[Interview 35: 31-year-old male; initial non-runner; 12 months attendance]

Socially, I think it's been great. I've met so many new friendly people which really motivates me to go.

I feel I have a more social element to my life.

[Interview 45: 39-year-old female; initial regular runner; 5 months attendance]

It is really nice because running around the lake you notice all the wildlife and often I see little ducklings and for some strange reason it encourages me to keep going.

[Interview 44: 35-year-old female; initial non-runner; 12 months attendance]

Once I'd finished and I realised that I'd actually run all the way and that was my first $5 k$, I felt really happy afterwards, and it sort of motivated me to go again the following week, and then to keep on going.

[Interview 5: 43-year-old female; initial non-runner; 33 months attendance]

If you can get 50 runs you get a red T-shirt. I know all these things are quite small in their way, but people are quite proud of them too because it is quite an achievement to have run fifty $5 \mathrm{k}$ runs.

[Interview 14: 52-year-old male; initial non-runner; 8 months attendance]

\section{Giving}

I was obviously struggling and she kind of, you know, supported me through the last lap, which was really nice. I mean I didn't know her and people do that all the time, you know, encourage people, complete strangers, but everybody's kind of there and there is a spirit to encourage people.

[Interview 4: 27-year-old female; initial non-runner; 27 months attendance]

Even if I'm not volunteering and not running I tend to go down just to support the others anyway...there are a lot of other people that do it as well.

[Interview 13: 48-year-old female; initial non-runner; 8 months attendance]

I mean she was obviously struggling, but she never stopped once throughout it and she just ploughed on and got through it, you know, and it was really motivating for me to see somebody doing that.

[Interview 10: 39-year-old male; initial non-runner; 17 months attendance]

I've seen how fast the first person went round - absolutely bombed it! That was quite good to watch them as well and I was like "One day I'll do that!"

[Interview 8: 44-year-old female; initial non-runner; 17 months attendance]

I get a lot more involved in the volunteering side of things and just the fact that it's become a lot more important to me because it's become more of a commitment to my friends and others who attend parkrun and not just about myself.

[Interview 47: 30-year-old female; initial non-runner; 34 months attendance]

I did buy a gazebo too for parkrun, cos it often rains, and I thought it was cheap enough and a good investment, as I'm so pleased with parkrun.

[Interview 30: 77-year-old male; initial regular runner; 92 months attendance] 
Table 5 Illustrative quotes of the contrast with traditional exercise options

\section{Contrast with traditional exercise options}

I like it because it's free. Exercise is very expensive which has prevented me from being physically active in the past. It provides a nicer atmosphere too...I'm not keen on the gym, it's not as nice, there's too many people staring at you and most of them are real fitness people who take it too seriously whereas parkrun has a more relaxed approach.

[Interview 46: 61-year-old female; initial occasional runner; 3 months attendance]

You don't feel like you're being watched or judged and it makes you feel happy and want to be there doing exercise. It brings about a totally different feeling to other times I've experienced exercise.

Sometimes sports can be quite exclusive and you have to have all the gear, or join something or have or pay for membership.

[Interview 43: 33-year-old female; initial non-runner; 4 months attendance]

I much prefer to be outside than inside. So I'd rather run in bad weather than go to a gym. We have a free gym at work and I don't use it. I'd rather be outside.

[Interview 3: 51-year-old female; initial non-runner; 34 months attendance]

Being in the gym makes me feel claustrophobic and it's just a weird environment to exercise in. I don't run to music, I just like being out in the elements being out in the wind, rain, and the park environment is very important.

[Interview 37: 44-year-old male; initial occasional runner; 5 months attendance]

It's not that easy just to go running or go to the gym by yourself, although some people might, but I like the community spirit, and I like doing it in the outdoors. It's an organised thing, it's something you go as a community to do, and there's motivation to go out and meet new people. But running by myself or going to the gym just wouldn't motivate me.

[Interview 34: 55-year-old male; initial regular runner; 6 months attendance]

And people kind of tend to talk to you more at parkrun as well, so they'll encourage you. I see the same faces in my body combat class, but I never speak to anybody there. There's two women who I stand next to nearly every time I go, and they talk to the same people and they don't talk to you. [Interview 9: 32-year-old female; initial non-runner; 17 months attendance] 